\title{
Phosphate Backbone
}

National Human Genome Research Institute (NHGRI)

\section{Source}

National Human Genome Research Institute (NHGRI). Phosphate Backbone.

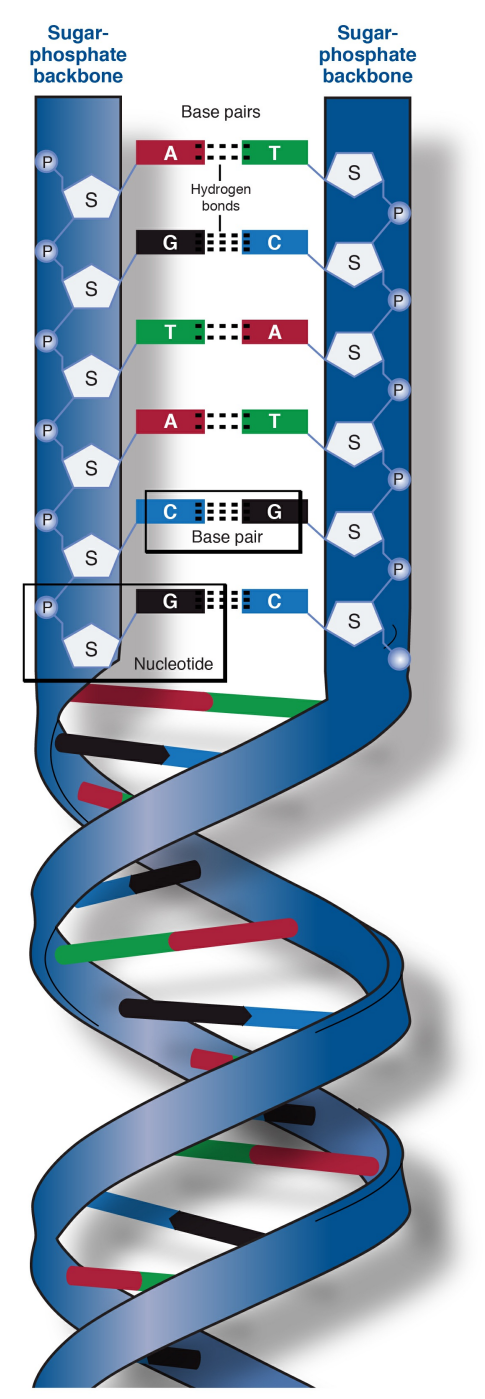

A phosphate backbone is the portion of the DNA double helix that provides structural support to the molecule. DNA consists of two strands that wind around each other like a twisted ladder. Each strand has a backbone made of alternating sugar (deoxyribose) and phosphate groups. Attached to each sugar is one of four bases--adenine (A), cytosine (C), guanine $(G)$, or thymine $(T)$. The two strands are held together by bonds between the 
bases, with adenine forming a base pair with thymine, and cytosine forming a base pair with guanine. 